\title{
ANÁLISE COMPARATIVA DE GUIAS TURÍSTICOS EM FORMATO DE APLICATIVO: LONELY PLANET E MTRIP
}

COMPARATIVE ANALYSIS OF TRAVEL GUIDES IN APP FORMAT: LONELY PLANET AND MTRIP

ANÁLISIS COMPARATIVO DE LAS GUÍAS DE TURISMO EN FORMATO DE APLICATIVO: LONELY PLANET Y MTRIP

\section{Marianna do Nascimento Brilhante}

Bacharel em Lazer e Turismo pela Universidade de São Paulo (USP)

brilhante.ps@gmail.com

Cynthia Corrêa

\author{
Doutora em Comunicação Social \\ Professora na Universidade de São Paulo \\ cynthia.correa@outlook.com \\ Data de Submissão: 21/12/2014 \\ Data de Aprovação: 02/06/2015
}

RESUMO: A tecnologia móvel ganha projeção como plataforma de distribuição de produtos e serviços turísticos. Entre as fontes de informação mais utilizadas pelos viajantes estão os guias turísticos, que se popularizam no formato de aplicativos para dispositivos móveis, visando manter o viajante informado e orientado de modo dinâmico. A pesquisa tem por objetivo analisar a estrutura dos aplicativos de viagens para dispositivos móveis, a partir de um estudo comparativo de caráter qualitativo e exploratório dos guias turísticos Lonely Planet e mTrip, respectivamente das empresas BBC Worldwide e Apple Inc. Trata-se de uma pesquisa baseada em revisão bibliográfica e na análise dos guias turísticos sobre a cidade de New York, considerando as seguintes categorias de análises: conteúdo informativo, $m$-Commerce, interatividade e versões multilíngues. Como resultados, verificase que, em geral, há similaridades entre os conteúdos apresentados pelos dois aplicativos. Todavia, nas outras categorias de análise, o guia mTrip destaca-se ao oferecer transações comerciais via dispositivo móvel, explorar o potencial de interatividade por meio de serviço de realidade aumentada e compartilhamento em mídias sociais, bem como ao disponibilizar versões em outros idiomas, de modo a ampliar o acesso a turistas de diferentes nacionalidades.

PALAVRAS-CHAVE: Turismo móvel. Aplicativos. Guias turísticos. 
ABSTRACT: Mobile technology has become popular as a distribution platform for tourism products and services. Among the most widely used sources of information by travellers, travel guides have become popular as apps for mobile devices. They are designed to keep travellers informed, and guide them dynamically. This research analyzes the structure of travel guide apps for mobile devices, based on a comparative, qualitative study of the Lonely Planet and mTrip travel guides produced by BBC Worldwide and Apple Inc., respectively. This research is based on a literature review, and on an analysis of travel guides of New York City. It considers the following categories: informative content, $\mathrm{m}$-Commerce, interactivity, and multilingual versions. The main results were that there are similarities in the content presented by both apps. However, in the other categories, mTrip guide had the advantage that it offers commercial transactions via the mobile device, exploring the potential of interactivity through reality augmentation services and by sharing information on social networks. This app also offered versions in other languages, expanding access to tourists of different nationalities.

KEYWORDS: Mobile tourism. Applications. Travel guides.

RESUMEN: La tecnología móvil se destaca como plataforma de distribución de productos y servicios turísticos. Entre las fuentes de información más utilizadas por los viajeros están las guías de viajes, que se han vuelto populares como aplicaciones para dispositivos móviles. Están diseñadas para mantener a los viajeros informados y orientados de forma dinámica. Esta investigación tiene como objetivo analizar la estructura de los aplicativos de las guías de viajes para dispositivos móviles. Se trata de un estudio comparativo de carácter cualitativo y exploratorio de las guías de viajes Planet y mTrip ofrecidas, respectivamente, por las empresas de la BBC Worldwide y Apple Inc. Esta investigación se basó en un estudio bibliográfico y en el análisis de guías de viaje de la ciudad de Nueva York, considerando las siguientes categorías: contenido informativo, m-Commerce, interactividad y versiones plurilingües. Como principales resultados, en general, hay similitudes relacionadas con el contenido presentado por ambos aplicativos. Sin embargo, en las otras categorías, el guía mTrip tiene algunas ventajas por ofrecer transacciones comerciales a través de dispositivo móvil, explorar el potencial interactivo a través del servicio de realidad aumentada y por el intercambio de información en las redes sociales. Además de ello, ofrece versiones en otros idiomas, con el objetivo de ampliar el acceso de los turistas de diferentes nacionalidades.

PALABRAS CLAVE: Turismo móvil. Aplicativos. Guías turísticas.

\section{INTRODUÇÃO}

atividade turística é marcada pela flexibilidade e capacidade de
adaptação. Por ser multifacetada, ela interage com diferentes
áreas do conhecimento, além de acompanhar as inovações tecnológicas. Dada à intangibilidade que caracteriza o setor, a informação é essencial no planejamento de viagens. Portanto, ao se constatar a necessidade de viajar, o processo de tomada de decisão de um viajante entra no seu segundo estágio, que seria a busca por informação relevante (AOQUI, 2003). 
Neste sentido, as Tecnologias da Informação e da Comunicação (TICs) são significativas para o gerenciamento e a distribuição de produtos e serviços turísticos de forma efetiva.

$\mathrm{Na}$ atualidade, ressalta-se o desenvolvimento de tecnologias móveis amplamente empregadas pelos viajantes independentes, que estão sempre conectados, sendo a associação entre turismo e tecnologia móvel nominada Turismo móvel ou m-Tourism (HUINEN, 2006; ALLERSTORFER, 2013). Diante da expansão da plataforma móvel no contexto do turismo, diversas pesquisas estão sendo promovidas, englobando análises sobre o impacto do uso de sistemas móveis em viagens (WANG; XIANG; FESENMAIER, 2014; SMITH et al., 2015), abordagens sobre a classificação de aplicativos utilizados no turismo (KENNEDYEDEN; GRETZEL, 2012), bem como estudos relativos a aplicativos para promoção de destinos, seja em formato de guias turísticos (FUENTETAJA et al., 2014; CORRÊA, 2014) ou de jogos eletrônicos, por meio das práticas de gamificação (XU et al., 2013; XU; WEBER; BUHALIS, 2014; CORRÊA; KITANO, 2015).

O avanço tecnológico, por meio da conexão sem fio à rede internet, oferece ainda perspectivas de crescimento para o Comércio móvel ou $\mathrm{m}$-Commerce e $m$-Tourism (SCHWINGER et al., 2005). No que se refere ao comportamento do novo consumidor ou viajante independente, ele é mais exigente e preocupado em otimizar o tempo (KOSAKA, 2009), perfil que vai ao encontro das potencialidades dos aplicativos de viagens, que permitem o acesso a todo tipo de informação de qualquer local e de forma contextualizada. Na rotina de busca por informação, os guias turísticos impressos são, desde o Grand Tour, uma das principais fontes de informação para os viajantes à procura de lugares para ficar, comer, visitar, etc. Assim, a migração dos guias turísticos para o formato eletrônico ocorreu de forma natural, seja por meio de blog de viagens, website ou mídia social. Por sua vez, no cenário do turismo móvel, os guias turísticos passam a ser distribuídos no formato de aplicativos para dispositivos como smartphones e tablets.

Ao observar que o novo consumidor organiza as próprias viagens e busca informações antes, durante e depois da viagem, com o auxílio cada vez maior de tecnologia móvel, apresenta-se uma pesquisa com o objetivo geral de analisar a estrutura de aplicativos de viagens para dispositivos móveis, a 
partir de um estudo comparativo dos guias turísticos Llonely Planet e mTrip, projetados em momentos distintos do avanço tecnológico por empresas de perfis diferenciados, e com ênfase na cidade de New York, destino selecionado para a comparação do material. Entre os objetivos específicos destacam-se: mapear o conteúdo informativo, avaliar as práticas de $m$-Commerce, examinar o aspecto da interatividade e verificar a existência de versões multilíngues.

A escolha do guia da Lonely Planet deve-se ao fato de ser uma marca atuante e popular no meio impresso. Nesse aspecto, verificar a transição para a plataforma móvel se torna interessante para análise. Por outro lado, o estudo do guia mTrip desenvolvido pela Apple Inc., ou seja, inserido completamente no ambiente tecnológico, pode apresentar características mais aproximadas ao panorama do turismo móvel. Ao colocar esse dois objetos de análise em contraposição, o estudo exploratório consegue levantar dados de pontos extremos sobre o assunto abordado.

Devido à escassez de estudos acerca de guias turísticos para a plataforma móvel em território nacional, optou-se pela pesquisa qualitativa e de caráter exploratório, de modo a proporcionar uma visão geral, de tipo aproximativo, envolvendo um levantamento bibliográfico sobre temas como turismo e tecnologia, turismo móvel, viajantesindependentes eguiasturísticos, doimpresso ao formato de aplicativos, além da análise comparativa dos aplicativos. Para Appolinário (2011), os dados obtidos em uma pesquisa qualitativa geram grande quantidade de informações que precisam ser organizadas. E a identificação de categorias, padrões e relações entre os dados permitem, assim, criar ou desvendar o significado desses dados por meio de uma interpretação. A análise tem com objetivo organizar os dados de forma a possibilitar o fornecimento de respostas ao problema proposto para investigação. Já a interpretação tem como objetivo a procura de sentido mais amplo das respostas, o que é feito mediante sua ligação a conhecimentos anteriormente adquiridos (GIL, 2008).

\section{TURISMO E TECNOLOGIA MÓVEL}

O relatório da Amadeus Future Traveller Tribes 2020 (2011) revela que o viajante exige níveis mais elevados de controle, conforto, segurança e 
personalização, e o avanço das TICs vai incrementar a habilidade dos provedores de viagens de modo a atender às expectativas dos consumidores. Dados da World Travel and Tourism Council - WTTC (2011) indicam que, graças à propagação da internet, os últimos anos foram marcados por um aumento significativo de viagens compradas on-line. O crescimento de uso da rede traz implicações expressivas para a indústria de viagens e turismo não apenas por facilitar o acesso à informação, mas por reduzir o tempo para a tomada de decisões. Uma em cada cinco pessoas organiza seu feriado/viagem em menos de cinco dias antes de viajar, aproveitando as ofertas de última hora.

Com relação aos mecanismos de coleta de informação, Prestipino (2006) comenta que, em geral, as redes de relacionamento pessoais são consultadas com mais frequência no planejamento de uma viagem. Os viajantes independentes preferem uma forma de levar/anotar informações durante a viagem que demandem baixo esforço e tenha grande flexibilidade. Por fim, enquanto viajam, optam por formas de comunicação direta para obter informação e, nesse caso, a internet figura como fonte de informação largamente empregada.

Se há pouco tempo o consumidor podia planejar uma viagem para qualquer lugar sem sair de casa (KOSAKA, 2009), hoje, com as tecnologias móveis, é possível programar a viagem fora de casa, em qualquer lugar do mundo. Com a praticidade de realizar pesquisas on-line, os turistas personalizam itinerários e pacotes, comparando preços de produtos e serviços. A tecnologia móvel aprimora o processo de tomada de decisão, pois os consumidores são capazes de pesquisar, reservar e revisar produtos em movimento (WTTC, 2011), gerando um fluxo mais intenso de informação atualizada e sem limites físicos. Para Fuentetaja et al. (2014), os sistemas móveis são chave para o consumo de uma enorme quantidade de informação sem fronteiras de tempo e espaço, ademais, o acesso à informação pode estar ligado precisamente ao contexto de tempo e local, tornando-se essencial para satisfazer as necessidades do usuário (LAMSFUS et al., 2013). Assim, o mapeamento do conteúdo informativo dos aplicativos torna-se necessário, já que a principal função de um guia turístico, impresso ou móvel, é fornecer informação.

O surgimento da computação móvel ocorreu em 1992, com a criação do Personal Digital Assistant (PDA) pela Apple Inc., no entanto, o produto não obteve 
ISSN: 1983-7151

sucesso por ser grande, pesado e caro. Em 1996, a U.S. Robotics lançou versões do Palm Pilot 1000 e 5000, que tiveram aceitação no mercado e lançaram as bases de toda uma plataforma de Palms, atingindo $80 \%$ do mercado mundial (TORRES, 2011). Na concepção do autor, sistemas de mobilidade ou sistemas computacionais móveis são aqueles que podem facilmente ser movidos fisicamente ou cujas capacidades podem ser utilizadas em movimento; normalmente, oferecem recursos e características que não são encontrados em sistemas comuns.

Em paralelo, Pellanda (2009) enfatiza a miniaturização de componentes eletrônicos e a expansão das redes sem fio, que deram origem a aparatos de comunicação móvel. Trata-se de uma abordagem que inclui o lugar (espaço) e a quantidade (tempo) de exposição à conexão por parte dos indivíduos. O fato da tecnologia móvel ser marcada pela facilidade de personalização amplia a identificação com o turismo, já que o viajante busca por produtos e serviços diferenciados.

Brown e Chalmers (2003) afirmam que o turismo apresenta um potencial considerável para o uso de tecnologia móvel. Hoje se vê esse potencial ser representado por meio da tecnologia dos smartphones e tablets. Atualmente, os dispositivos móveis tornaram-se indispensáveis na bagagem do turista, já que estão economicamente acessíveis e permitem acesso quase irrestrito a informações úteis com um bom nível de interatividade (ANDRADE; MAIA; MAIA, 2011). Vale dizer que a popularização tanto dos smartphones quanto dos tablets teve início com a empresa Apple Inc., em 2008, com os Iphones e, em 2010, com os tablets Ipads. Ambos os dispositivos são qualificados como novas plataformas de computação que se aproveitam da personalização e da localização de uma maneira nova (NORM..., 2011).

De acordo com Pellanda (2009), essa nova forma de apropriação da localização por meio do Global Positioning System (GPS), integrada aos dispositivos Always on, provoca uma mutação no conceito de mídias. Ademais, "Relações entre pessoas, informações e espaços físicos foram conectadas de uma forma inédita" (2009, p. 96). Por exemplo, os mapas interativos on-line ou off-line dispõem de serviços de geolocalização que, a partir de dados sobre a posição de um objeto em um espaço físico, como latitude, longitude e altitude, oferecem informação 
contextualizada, ou seja, conforme a localização do usuário (JESUS; SILVA, 2009). Isso significa que a internet móvel não se resume a acessar um site via celular, a proposta é transformar e adaptar esse acesso de modo que não seja entendido como uma miniaturização da Web:

As categorias de aparatos móveis tablets e smartphones, por sua vez, mostraram-se mais adequadas para conteúdos formatados para aplicativos nativos ou Apps [...]. Apps possuem interfaces desenhadas para cada função e podem acessar funções nativas dos aparelhos como sensores GPS ou sensores de gravidade que indicam a posição que o usuário está segurando o aparelho [...]. Os Apps estão proporcionando um ambiente para novas formatações de conteúdos. (PELLANDA, 2011, p. 97).

Torres (2011) complementa que o aplicativo é o componente responsável pela maioria das inovações e usos diferenciados considerando aspectos como usabilidade e interatividade, tornando o dispositivo móvel mais flexível e útil. Raciocínio partilhado por Jesus e Silva (2009), ao assegurarem que a inovação dos dispositivos móveis está na apresentação dos conteúdos, sendo o serviço de realidade aumentada o principal responsável. O recurso de realidade virtual permite que o utilizador obtenha informações sobre o mundo real por meio de objetos virtuais sobrepostos ou combinados a imagens reais. Portanto, não ocorre imersão em um mundo virtual, tratando-se de um suplemento da realidade, a ponto do utilizador, idealmente, ter a percepção da coexistência de objetos virtuais e reais em um mesmo espaço (JESUS; SILVA, 2009).

Dessa forma, aplicativos são criados para atender os interesses dos usuários, mediante a disponibilização de conteúdos em novas interfaces. Além dos elementos-chave como dispositivos móveis e aplicativos, há um intermediário essencial para garantir a expansão desse mercado, que são os sistemas operacionais para aplicativos. Os líderes mundiais são, respectivamente, o Android da empresa Google Inc. e o iOS da Apple Inc.

\section{GUIAS TURÍSTICOS: DO IMPRESSO AO APLICATIVO}

O uso da informação para planejamento de uma viagem, bem como para a elaboração de itinerários, é uma realidade para todo viajante, assim, a consulta 
a guias turísticos pode ser feita antes, durante e depois da viagem. No modelo padrão, conforme Brown e Chalmers (2003), a busca antes da viagem pode ser útil para estimular o indivíduo a escolher um destino, à medida que pesquisa informações acerca de transporte, hospedagem, alimentação, eventos, etc. O durante também se diferencia pela busca desse tipo de informação, pois o viajante independente gosta de manter o itinerário flexível. O depois se caracteriza pela transmissão da informação contida no guia impresso para novos viajantes que, além das informações oficiais, podem se beneficiar das anotações de outros.

Na história, o primeiro registro de um guia é datado do ano de 1130, o chamado Guia do Peregrino consistia em diversos manuscritos elaborados para aqueles que faziam o caminho de Santiago de Compostela (CAMARGO, 2002). No século XVII, o aumento da importância de grupos que visitavam os centros culturais e as grandes cidades incentivou a publicação do Guia Fiel nas Viagens pela França por Saint Maurice, o primeiro guia turístico impresso (DIAS; AGUIAR, 2002), cuja publicação estreitou a relação entre turismo e comunicação. O progresso da atividade turística une-se ao incremento da comunicação, com a presença da escrita e o surgimento de uma sociedade capitalista, tanto que nos anos seguintes são lançados guias impressos na Inglaterra (RODRIGUES, 2008).

De fato, as publicações apareceram nessa época, porém, em forma de diários ou relatos de viagem. Entre os séculos XVII e XVIII, a Europa representava o centro do desenvolvimento capitalista (SALGUEIRO, 2002). No final do século XVIII, houve o crescimento do tour continental, Grand Tour, promovido para os filhos da classe média urbana formada por burgueses prósperos e emergentes do setor de serviços (UNY, 1991). O Grand Tour envolvia uma viagem a Paris e um circuito pelas principais cidades italianas, visando ampliar o conhecimento sobre a história e a arte dos antigos. A visita implicava a escrita de um diário de viagem, com a ilustração de monumentos observados, para ser publicado no retorno do viajante, o que ampliava o conhecimento e despertava o interesse dos leitores para novos projetos de viagem (SALGUEIRO, 2002).

Camargo (2002) emprega o termo literatura de viagens para especificar esse gênero de leitura. As anotações feitas por guias intérpretes durante as viagens 
pelos Alpes Franceses serviam como conteúdo valioso para guiar os viajantes, com descrição de itinerários, lugares para descanso e tempo de viagem (NOVA, 2008). Algo um pouco mais aproximado do que é apresentado pelos guias impressos atuais. Ressalta-se que Thomas Cook no século XIX lançou um guia chamado Handbook of trip, que descrevia um itinerário de viagem (REJOWSKI, 2002). E, a partir do século XIX, surgem os guias impressos conhecidos hoje, informativos de forma objetiva e organizados em categorias (SALGUEIRO, 2002).

Existe uma variedade de opções de guias turísticos visando atender às necessidades de cada viajante. Há guias escritos por especialistas, outros publicados por pessoas que viajam o mundo por conta própria e guias divulgados por editoras. Devido ao avanço da internet, as principais publicações de guias turísticos migraram para a World Wide Web, disponibilizando materiais eletronicamente. Uma das editoras mais populares entre os viajantes, a Rough Guides, com 30 anos de existência, é um exemplo de empresa que adaptou seus guias turísticos ao meio eletrônico (ROUGHGUIDES, online). Outra editora famosa é a Lonely Planet, criada em 1973. Hoje a marca Lonely Planet reúne mais de 650 publicações - guias, ebooks, phrasebooks e edições para distintos nichos de mercado. A editora fornece informações sobre costumes, história, religião, arte, política e etiqueta, para evitar que o viajante cause impactos negativos no destino. No site da marca, as publicações são produzidas em diversos idiomas, representando um diferencial, pois a carência de conteúdo em idiomas variados limita o alcance do produto (DIAZ-LUQUE; CORRÊA, 2012).

Sobre a relação turismo e meio eletrônico, destacam-se os blogs de viagens, como espaço para o compartilhamento de experiências. Ao analisar o relato de impressões sobre um lugar, Freire-Medeiros, Menezes e Nunes (2008, p. 2) dizem que: "Frustrações, seduções e estranhamentos diante do Outro podem até assumir um tom confessional ou introspectivo, mas desde o início são pensados como experiências a serem compartilhadas, muitas vezes antes mesmo do retorno do autor ao local de origem."

Hoje, o compartilhamento de informações sobre viagens ocorre ainda via mídias sociais, como Facebook (http://www.facebook.com/), Twitter (http:// twitter.com/) e Pinterest (http://pinterest.com/). Assim, ao se fazer um paralelo entre as publicações impressas e a rede internet como fonte de informação, 
Mariuzzo (2009) aponta que a busca por informações on-line tem caráter de pesquisa e serve para resolver questões de ordem prática, como reserva de voos e hotéis. Por outro lado, há turistas que se sentem mais confortáveis com o guia à mão, por avaliarem a informação capturada on-line fragmentada. Já com o guia impresso é diferente, a informação está reunida e organizada de forma a facilitar a viagem.

Apesar da diferença de proposta entre os formatos impresso e eletrônico, as editoras buscam transmitir informações via sites com credibilidade. Atualmente, com a tecnologia móvel, a divulgação de guias turísticas conta com uma nova plataforma, os aplicativos para dispositivos móveis, que apresentam uma interface mais compacta, além de serem atualizados em tempo real, ao contrário das publicações impressas.

Na área de turismo existe uma demanda por sistemas de informática capazes de fornecer a viajantes informações atuais e relevantes conforme os locais de visitação, levando a uma substituição dos tradicionais guias impressos por guias digitais interativos (RODRIGUES; BECO; TEIXEIRA, 2011). Não é à toa que renomadas editoras estão buscando a tecnologia móvel como uma forma de distribuir informações, nesse sentido, tanto a Rough Guides quanto a Lonely Planet já disponibilizam aplicativos de viagens. Ademais, recentemente a empresa Apple Inc. lançou o aplicativo mTrip, projetado para dispositivos móveis, com a proposta de organizar todo o itinerário de viagem e orientar o usuário como um guia de turismo profissional poderia fazer (MTRIP, on-line).

Dado o dinamismo dos dispositivos, os guias em formato de aplicativo têm capacidade de conduzir ou mostrar o caminho ao viajante, apontar atrativos de interesse, além de fornecer dados precisos sobre a destinação. Assim, a noção de guia turístico como simples compilação de informações pode ter sido mudada ou ampliada em decorrência da criação de aplicativos para dispositivos móveis (ANDRADE; MAIA; MAIA, 2011).

\section{MÉTODOS E TÉCNICAS}

Para o desenvolvimento desta pesquisa, de caráter qualitativo e exploratório, foi realizada inicialmente uma revisão bibliográfica de conceitos-chave para o 
estudo, como a relação entre turismo e tecnologia, turismo móvel, viajantes independentes, guias turísticos, do impresso ao aplicativo. Na sequência, houve a seleção de dois aplicativos de guias turísticos para serem comparados. Foram escolhidos aplicativos sobre a cidade de New York, destino renomado mundialmente, disponibilizados pelas empresas BBC Worldwide, por meio da marca Lonely Planet tradicional no turismo, e Apple Inc., líder mundial em computação e eletrônica.

A marca Lonely Planet nasceu em 1973 após uma viagem dos fundadores Tony e Maureen Wheeler, sendo a pioneira na publicação de guias e livros para viajantes. A partir de 2000, a marca de propriedade da BBC Worldwide lançou guias de bolsos com assuntos variados, como World Food; Read This First (guias pré-viagens) e Out To Eat (guias de restaurantes). Atualmente, a Lonely Planet oferece mais de 650 livros e guias publicados em 14 idiomas, retratando mais de 150 países, uma revista de viagens mensal e ainda o canal de televisão Lonely Planet Television. Os guias da Lonely Planet foram os primeiros a ter versões eletrônicas para iPhone, com aplicativos que oferecem mapas, fotos e guias de idiomas com as frases mais usadas.

Já o aplicativo mTrip foi criado em 2011 e desenvolvido pela Apple Inc. em parceria com a empresa de guia de viagens Falk, que forneceu o conteúdo sobre os destinos. Conforme a descrição do aplicativo, o mTrip é um guia de viagens inteligente, que permite o compartilhamento de informações pelos usuários. O guia de viagem mTrip é divulgado como uma nova opção para o viajante organizar sua viagem, levando-o a cada destino como se fosse um autêntico guia particular (MTRIP, on-line). O aplicativo usa a mais recente tecnologia para telefone inteligente, visando oferecer variados serviços ao usuário, e está disponível para os sistemas operacionais Android e iOS.

Dessa maneira, buscou-se comparar os dois aplicativos de guias de viagem, Lonely Planet e mTrip, pela diferenciação de perfil entre as empresas desenvolvedoras. Além de analisar esses aplicativos buscando semelhanças com as características básicas encontradas em guias impressos, a pesquisa mantém um enfoque no que tange ao desenvolvimento tecnológico e às suas potencialidades. Ao examinar os aplicativos, a proposta central foi identificar na prática essa nova forma de distribuição da informação, tão importante para o 
setor turístico, conforme o Relatório da Henley (2011), que indica as principais áreas de desenvolvimento tecnológico móvel, entre elas:

- Oferecimento de informações em tempo real, de acordo com as necessidades e a localização do viajante.

- Crescimento do nível de tecnologias de informação visual mais barata e sofisticada, tecnologias provenientes de games e de realidade virtual, que futuramente permitirão que o viajante veja e experimente um local de destino antes da viagem.

- Tecnologias de linguagem permitirão ao viajante fazer solicitações verbais, tradução semântica, entre outros.

Tais aspectos possibilitam que o viajante tenha uma gestão mais flexível de sua viagem, além disso, nota-se que certas previsões já estão em uso no meio turístico.

A análise comparativa também levou em consideração elementos comuns presentes no planejamento de uma viagem, tanto antes, durante e no pós-viagem. Para esta pesquisa, a comparação foi efetuada por meio de um smartphone da Apple Inc., o iPhone 4S, devido à disponibilidade do aparelho e por ser voltado para a plataforma iOS, na versão iOS 6, permitindo o acesso ao guia mTrip, além da empresa ter sido pioneira quanto à massificação dos smartphones.

Por não haver muitos estudos específicos sobre guias de viagem para aplicativos móveis em nível nacional, propôs-se uma pesquisa de natureza exploratória. Este tipo de pesquisa é realizado especialmente quando o tema escolhido é pouco explorado, tornando-se difícil a formulação de hipóteses precisas e operacionalizáveis (GIL, 2008).

Já a análise comparativa pode até ser considerada superficial, no entanto, aponta similaridades e diferenças, além de ser considerada inerente ao campo das Ciências Sociais (SCHNEIDER; SCHIMITT,1998). Por ser uma pesquisa de caráter qualitativo e restrita ao exame de dois guias, não existe a pretensão de se fazer generalizações no que diz respeito às características dos aplicativos. 
Ao considerar os objetivos deste trabalho, foram adotadas as seguintes categorias de análise para organizar, comparar e interpretar os dados: o conteúdo informativo, o $m$-Commerce, a interatividade e as versões multilíngues a partir de uma adaptação da técnica aplicada aos websites de turismo oficial das cidades-sede da Copa do Mundo de Futebol de 2014 no Brasil pelos autores Díaz-Luque e Corrêa (2012). Na sequência, as categorias de análise são apresentadas em detalhes:

1. A primeira categoria de análise, conteúdo informativo, aborda a informação contida nos aplicativos, contemplando os elementos a seguir: como chegar ao destino (aeroportos, rodovias, ferrovias, portos) e transporte no destino, atrativos turísticos e agenda de eventos, referências de empresas do turismo e, por fim, informação de utilidade pública (acessibilidade, segurança e emergência).

2. A segunda categoria investiga as práticas de $m$-Commerce, ou seja, examina se os aplicativos oferecem sistemas de reserva on-line para facilitar o planejamento da viagem, como sistemas de terceiros integrados (Hotel.com, Booking.com) ou sistemas próprios de reserva da Lonely Planet e da mTrip.

3. A terceira categoria avalia os aspectos de interatividade dos aplicativos, ao verificar os recursos para estabelecer interação com o viajante, por meio de endereço físico, número de telefone, fórum, acesso às mídias sociais (Twitter, Facebook), a sites de compartilhamento de imagens e vídeos (Flickr, Pinterest, YouTube), blogs e sites de viagens (TripAdvisor). Além de conteúdo on-line, aborda-se a interatividade baseada em elementos característicos da tecnologia móvel como realidade aumentada, acesso a conteúdo off-line, GPS, bem como a criação de rotas e itinerários em tempo real.

4. A última categoria confere se os aplicativos oferecem versões dos guias turísticos em idiomas diferentes ao falado no destino, pois o ideal é que viajantes de outros países possam utilizá-los.

As categorias de comercialização e interatividade dizem respeito à miniaturização e às novas formas de interação. Como o viajante tem buscado facilidade na maneira de planejar e se contextualizar em um destino, a categoria de comercialização verifica se os aplicativos da Lonely Planet e da Apple Inc. 
acompanham e/ou exploram essas características. A relação entre fornecedor e consumidor pode ser feita de maneira direta ou indireta. Um exemplo da distribuição direta seria por meio de telefone ou website da empresa, já a indireta seria por meio de agências ou operadoras (LOHMANN, 2008).

Consequentemente, a categoria de comercialização observa os seguintes itens: sem informação de hospedagem; com informação e contato; links para websites de sistemas de reserva; com sistemas de reserva externo integrado ao aplicativo e sistema próprio de reserva integrado.

Tanto na fase pré-viagem quanto durante a viagem, o viajante pode buscar informações sobre acomodação, uma vez que ele gosta de manter seu itinerário flexível (BROWN; CHALMERS, 2003). Assim, a flexibilidade proporcionada pela mobilidade é uma aliada do mecanismo de comercialização. Os viajantes têm smartphones capazes de prover pagamentos, o resultado dessa junção é o desenvolvimento do $m$-Commerce, baseado na tecnologia móvel para comprar bens e serviços (HENLEY..., 2011).

A categoria de interatividade analisa como os canais de comunicação são disponibilizados e também a presença de realidade aumentada, conteúdo offline, GPS, rotas em tempo real e itinerário, fatores que representam a inovação nos dispositivos móveis (JESUS; SILVA, 2009).

\section{ANÁLISE COMPARATIVA}

A seguir, são divulgados os resultados das análises realizadas em setembro de 2014, de acordo com as categorias definidas em Métodos e Técnicas.

\section{CONTEÚDO INFORMATIVO}

Na categoria que aborda o conteúdo informativo dos aplicativos, foram enfatizados os seguintes elementos: como chegar/transporte no destino, atrativos, incluindo agenda de eventos, empresas turísticas e informação de utilidade pública. 


\section{COMO CHEGAR/TRANSPORTE NO DESTINO}

Ao se constatar a necessidade da viagem, o processo de tomada de decisão entra no seu segundo estágio, que seria a busca por informação relevante (AOQUI, 2003).

No que se refere à informação sobre como chegar a New York por meio de aeroportos, rodovias, ferrovias e portos, ambos os guias indicavam formas de acesso a aeroportos, rodovias, ferrovias. Com relação a portos, apenas o guia Lonely Planet disponibilizou esse tipo de informação. Os aplicativos ofereciam informações que vão além de links, endereços e telefones para contato, com parágrafos detalhados acerca dos três principais aeroportos (John F. Kennedy International Airport, Newark Liberty International Airport e La Guardia Airport).

Os dois guias forneciam indicações aos viajantes sobre como se locomover para chegar e sair dos aeroportos, como informações de preços e contatos, dados de empresas de táxi, car-service, serviço de ônibus expresso, sharedtaxi e transporte público. Havia ainda informação do tempo gasto em trajetos para os aeroportos, dicas sobre a melhor escolha de deslocamento conforme o aeroporto, valores de gorjeta para os motoristas e até indicação do percurso a ser feito pela cidade. Sobre o terminal de ônibus, era disponibilizada uma lista das empresas que operam no local.

Os dois guias apresentavam diversas formas para o viajante se locomover pela cidade, seja a pé, por meio do sistema MetroCard, ônibus, táxi, carro, bicicleta e balsa. O aplicativo Lonely Planet também oferecia opções de locomoção via motocicleta e trem, acompanhadas do contato das empresas que disponibilizam o serviço. Ambos tinham mapa de metrô integrado ao aplicativo, todavia, o mTrip traz dicas de como usar e interpretar o mapa e informações sobre os tipos de passes de transporte público. Ademais, em todos os locais turísticos, como atrativos, hotéis, restaurantes, o aplicativo mTrip informava como chegar, sugerindo estações de metrô próximas, assim como pontos de ônibus.

De acordo com pesquisa da Prosper Mobile Insights (FMDLA, on-line), a maioria dos usuários de dispositivos móveis os utiliza para checar e-mails e fazer pesquisas via internet. No caso de um viajante que busca informações iniciais sobre um destino, ambos os aplicativos conseguem ser ótimas fontes de pesquisa. 
Nos aplicativos, existiam informações relativas ao entorno natural da cidade, zonas comerciais, museus, monumentos, bem como dados sobre a história da cidade e a gastronomia. Já informações sobre agenda cultural e festas só foram encontradas no guia Lonely Planet.

Torna-se interessante registrar que havia informações para diferentes nichos de mercado em ambos aplicativos, por exemplo, na opção de restaurantes era possível escolher o melhor restaurante vegetariano ou o mais barato. Existem ainda categorias de "O que fazer" voltada para o público de Gays, Lésbicas e Simpatizantes (GLS), além de "O melhor para mulheres" e "Escolha da Lonely Planet". Também existiam informações sobre destinos próximos como Long Island, New Jersey Shore, Upstate New York e Hudson Valley no guia Lonely Planet, além de dados sobre excursões. As rotas turísticas ou city tours eram bem descritas no guia Lonely Planet e somente citadas no mTrip.

Brown e Chalmers (2003) categorizam os problemas dos viajantes em decidir: o que fazer, como fazer e quando fazer, aspectos que necessitam de informações para que sejam solucionados. Assim, verifica-se que, apesar de haver diferenças quanto à quantidade de informações, os aplicativos parecem solucionar esse tipo de problema. O mTrip vai além ao se preocupar em atender outros nichos dentro do segmento de viajantes.

\section{EMPRESAS DE TURISMO}

Os aplicativos ofereciam informações para o viajante sobre restaurantes e bares e meios de hospedagem, serviços avaliados como fundamentais para o viajante. O mTrip divulgava dados adicionais sobre acomodação, como média de preço em diferentes moedas, serviços básicos disponíveis nos quartos, etc. Já as agências de viagens foram apenas mencionadas na categoria de transportes no guia Lonely Planet.

Por sua vez, não foram citados serviços de rent a car em nenhum dos aplicativos, porém, ambos esclareciam que não era necessário o uso de carros 
em New York. Dessa forma, tanto o mTrip quanto o Lonely Planet explicavam por que não era recomendado o aluguel de carros, justificando a ausência de informação sobre esse tipo de serviço.

Sobre o conteúdo informativo dos aplicativos, é importante ressaltar um aspecto de usabilidade, uma vez que novos consumidores, viajantes experientes, sofisticados e exigentes, de um modo geral, preferem usar a internet para obter informações. Nessa linha, a tecnologia móvel chama atenção por ser uma fonte de informação compacta, flexível e objetiva (TORRES, 2011; JESUS; SILVA, 2009). Hoje, o viajante não está preso ao desktop, tendo a liberdade de acessar todo tipo de informação a qualquer momento, transformando a maneira de organizar, planejar e reunir informações para a viagem.

Nessa abordagem, os aplicativos diferenciavam-se, porque o guia Lonely Planet (Figura 1) apresentava informações em longos parágrafos e, pelo conteúdo descrito, aproximava-se mais de um relato de viagem (NOVA, 2008). Enquanto o mTrip (Figura 2) apresentava o conteúdo no formato de fichas técnicas compactas e, na maioria das vezes, oferecia resumos sobre os locais.

Figura 1 - Times Square

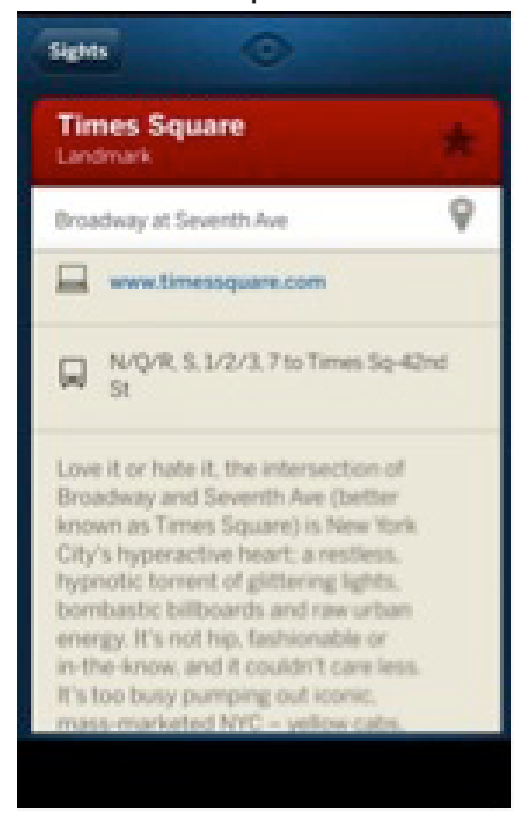

Fonte: Guia Lonely Planet
Figura 2 - Times Square



Fonte: Guia mTrip

No entanto, caso o viajante busque textos descritivos de cada atrativo turístico da cidade de New York, como o modelo adotado pelo Lonely Planet, o guia mTrip disponibilizava uma categoria voltada para uma leitura mais extensa. 
Ao colocar os viajantes em foco, deve-se lembrar que preferem uma forma de levar/anotar informações que demande baixo esforço e alta flexibilidade (PRESTIPINO, 2006), por isso os aplicativos mostram-se adequados.

Ao comparar os aplicativos, notou-se a ausência de imagens no guia Lonely Planet, com exceção da página inicial. Trata-se de uma deficiência do aplicativo, afinal imagens e textos são primordiais para a descrição de um local, sobretudo, na fase da pré-visita (BROWN; CHALMERS, 2003). Ademais, ao analisar a vinculação entre escrita e imagem nos diários de viagem, Salgueiro (2002) concluiu que a escrita e a ilustração despertavam o interesse dos leitores para novas viagens.

Na distribuição de conteúdo, o guia Lonely Planet dividia as informações de acordo com as regiões da cidade. Ao escolher um bairro específico, o usuário é direcionado para uma lista de opções sobre o que fazer na área com opções de: overview (visão geral), highlights (destaques), sights (atrativos), eating (gastronomia), drinking and nightlife (bares e vida noturna), entertainment (entretenimento), shopping (compras), sports and activities (esportes e atividades) e sleeping (hospedagem). Cada categoria temática é organizada com os locais em ordem alfabética. Há facilidade de busca por filtro, por exemplo, em gastronomia, o usuário pode fazer a consulta por tipo de comida e, ainda, pesquisar com base em preço e distância do local.

Algo semelhante ocorre com o guia mTrip que, além de filtrar a informação por tipo de comida, faz uma divisão por ordem alfabética, área, distância, popularidade e preço. Esse processo de busca personalizado estava disponível em todos os tópicos de informações turísticas e as subcategorias variam de acordo com o tema.

Como visto, nos dois aplicativos, as informações são divididas em categorias temáticas e apresentam descrições dos locais, números de telefones e links para contato, ou seja, mantêm características dos guias impressos, porém, são informativos de maneira mais objetiva, sistematizados e organizados em subcategorias e seções específicas que facilitam a consulta (SALGUEIRO, 2002), sem contar a atualização constante, que se torna crucial, pois todo o processo da viagem está apoiado na busca por informação. Essa fase de levantamento 
não se limita a um período específico e varia de acordo com as necessidades surgidas no decorrer da viagem (BROWN; CHALMERS, 2003).

\section{INFORMAÇÃO DE UTILIDADE PÚBLICA}

Ambos os aplicativos apresentavam um diretório de guia de viagens com uma série de informações adicionais úteis para o viajante. Por exemplo, o mTrip disponibilizava um serviço de conversão de moedas, informações sobre clima e dicas sobre como se locomover com segurança na cidade. Já o Lonely Planet oferecia informações sobre documentos oficiais para viajar, alfândega, contatos de embaixadas e consulados, caixas eletrônicos e uso de cartões de crédito, horário comercial, lugares para revelar filme de máquinas fotográficas analógicas, serviços médicos e correios. Há ainda recomendações de segurança, informações para viajantes em busca de trabalho na cidade, lista de telefones úteis, fuso horário, voltagem de energia elétrica, acesso à internet, mídia como jornais e revistas em New York e até indicação de sanitários públicos.

Em geral, o guia turístico se constitui em um manual ao compilar informações sobre os principais atrativos do destino. Entretanto, ao examinar esses dois aplicativos, verificou-se que procuram oferecer além da informação básica centrada em atrativos turísticos, pois há uma diversidade de informações úteis para orientar os turistas em casos de urgência e emergência, na perspectiva de guias digitais interativos, como comentado por Rodrigues, Beco e Teixeira (2011). Ademais, o viajante precisa decidir sobre o que fazer, como fazer e quando fazer (BROWN; CHALMERS, 2003) em qualquer circunstância.

Com relação ao turismo acessível, que engloba informações específicas acerca das instalações e dos equipamentos para atender pessoas com deficiência, apenas o guia Lonely Planet oferecia informações sobre como a cidade de New York estava se adaptando, o contato do escritório da prefeitura para saber os locais que detinham estrutura para atender o público e outros sites com esse tipo de suporte. 
A internet e as TICs alteraram os hábitos de consumo, à medida que milhões de pessoas efetuam transações comerciais on-line; atuando como pontes entre produtos, serviços e usuários. Ao apostar nas facilidades da tecnologia móvel, o novo consumidor/viajante independente espera que mecanismos de compras sejam oferecidos durante toda a viagem. Os viajantes têm smartphones capazes de prover pagamentos e o resultado dessa junção é o desenvolvimento do $m$-Commerce, baseado na tecnologia móvel para comprar bens e serviços (HENLEY..., 2011).

Tanto na fase pré-viagem quanto durante a viagem, o viajante pode buscar informações sobre produtos e serviços, uma vez que prefere manter o itinerário flexível (BROWN; CHALMERS, 2003). Assim, a flexibilidade de roteiro garantida pela mobilidade é forte aliada para o consumo por meio de dispositivos móveis.

Como resultado da análise sobre as práticas de $m$-Commerce, foi verificado que os dois aplicativos oferecem informação e contato de meios de hospedagem, lojas, bares, restaurantes, etc. No caso do guia Lonely Planet, há apenas o número de telefone e o site de hotéis, não permitindo qualquer tipo de reserva via aplicativo.

Figura 3 - Reserva de hotel

mtip NEW YORK
(1) Shopping
Hotels
Others
Book your hotel
() Add a place
(i) General Information
(])

Fonte: Guia mTrip.
Figura 4 - Ferramenta Booking.com

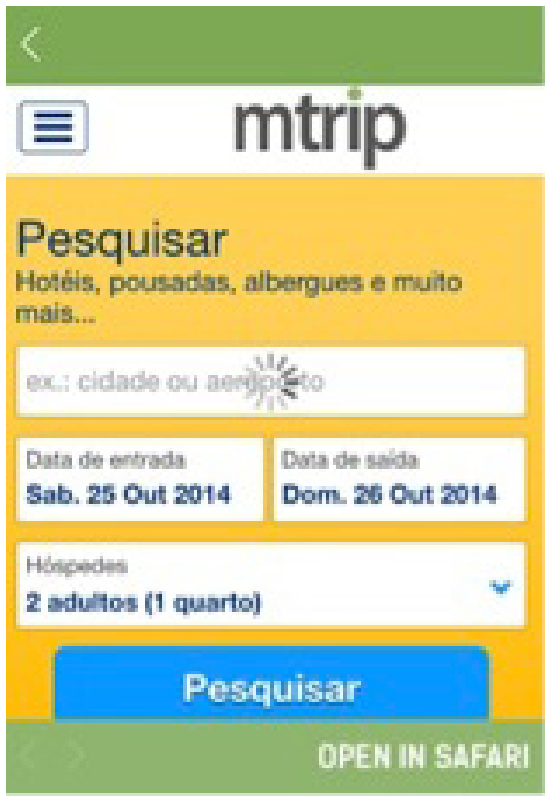

Fonte: Guia mTrip. 
Já o aplicativo mTrip disponibiliza o endereço dos meios de hospedagem, com informações sobre voltagem de energia elétrica, quantidade de quartos, etc., além de inovar ao oferecer a possibilidade de fazer reserva em hotel pelo próprio aplicativo (Figura 3). Ao selecionar determinado meio de hospedagem, o usuário pode fazer a reserva do quarto ou, caso opte por uma busca mais abrangente, pode realizá-la usando a ferramenta personalizada do mTrip em parceria com a Booking.com (Figura 4). Há ainda a opção de sair do aplicativo e fazer a reserva por meio de uma página Web. Nesse sentido, o mTrip consegue ultrapassar as funcionalidades básicas de um guia impresso. Lohmann (2008) indica que a relação entre fornecedor e consumidor pode ocorrer de forma direta ou indireta. Um exemplo da distribuição direta seria por meio de telefone ou website da empresa, como se observa no Lonely Planet, enquanto a indireta seria por meio de agências ou operadoras.

A presença de um canal de distribuição adequado é relevante para toda a atividade, pois os viajantes podem adquirir informações de diversas fontes e ainda utilizar o serviço de um intermediário para facilitar o processo de compra e troca de informações (KOSAKA, 2009). No momento em que os viajantes sentem-se cada vez mais confortáveis em comprar por meio de dispositivos móveis (WTTC, 2011), o aplicativo mTrip acaba por oferecer mais vantagens.

INTERATIVIDADE

Quanto ao potencial de interatividade explorado pelos aplicativos de guias de turismo, foram observados os canais de comunicação colocados à disposição dos viajantes, desde número de telefone, e-mail, fórum, mídias sociais, sites de compartilhamento, blogs e sites de dicas de viagens. Os dois aplicativos apresentam os respectivos números de telefone e e-mails para contato. Sobre os telefones para contato, tanto o guia mTrip quanto o Lonely Planet oferecem links para que a ligação seja realizada diretamente via dispositivo do viajante. Detalhes assim colaboram para a praticidade almejada durante toda a viagem.

Como visto, o contexto de uma viagem divide-se em pré, durante e pós, contudo, hoje se compartilham imagens, lembranças e dicas em todos essas fases, representando uma oportunidade ímpar de se informar por meio da 
percepção de outros e, principalmente, sem a interferência de empresas que atuam nos destinos. Cada impressão de um viajante é uma experiência a ser compartilhada, seja frustração, surpresa, por isso é comum encontrar blogs com essa finalidade (FREIRE-MEDEIROS; MENEZES; NUNES, 2008).

Por meio da análise, não foram identificados nos aplicativos canais de comunicação de caráter coletivo, como fórum e blogs. No que se refere a mídias sociais, um dos canais de comunicação mais populares, não há nenhum registro no guia da Lonely Planet, não existindo qualquer forma de compartilhamento via aplicativo. Algo lamentável ao considerar que os viajantes contam com a tecnologia móvel para ter acesso a informações de modo instantâneo e estabelecer conexões via mídias sociais, visando ao compartilhamento de opiniões, fotos e vídeos em tempo real.

Kosaka (2009) comenta o fato de que a internet vem se consolidando ao longo do tempo como um importante canal de distribuição de serviços e de informação, apontando para a alta possibilidade de colaboração dos usuários em tempo real, tornando-os tanto autores como leitores, dinamizando as relações de busca e troca.

O guia mTrip permite o compartilhamento da viagem por meio da mídia social Facebook, por e-mail e também via site do próprio guia, no qual o usuário pode criar um perfil e armazenar todas as informações da viagem. O aumento da mobilidade é impulsionado pelas mídias sociais, quando a experiência on-line passou de simples busca por informações para a efetiva troca e compartilhamento de relatos. Logo, comentários e fotos sobre viagens, bem como conteúdo de blogs e de mídias socais influenciam no modo como viajantes no geral interagem entre si. A autonomia do usuário em gerar conteúdo demonstra que os turistas não precisam confiar apenas em descrições oficiais dos destinos, mas acessar informações de todas as pessoas que de fato tiveram a experiência que o viajante almeja ter (WTTC, 2011).

Existe na página inicial do guia a função de itinerário, assim, o usuário pode adicionar as datas de início e fim da viagem e escolher uma acomodação na lista do guia. Em seguida, o aplicativo oferece a opção de acrescentar manualmente os locais que se pretende visitar (Figura 5) ou usar o Trip Genius, um sistema 
que cria um itinerário automaticamente, conforme as preferências definidas para cada período do dia (Figura 6). Embora viajantes independentes gostem de manter os itinerários flexíveis e sem muito planejamento, esse recurso é útil por possibilitar alterações durante toda a viagem, além do elevado nível de personalização exposto (NORM..., 2011).

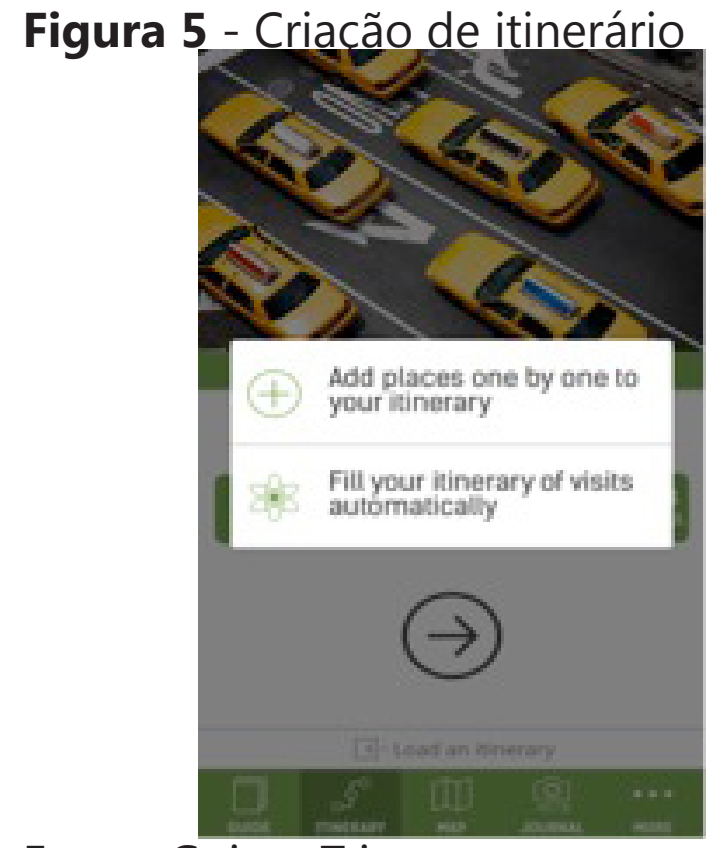

Fonte: Guia mTrip.

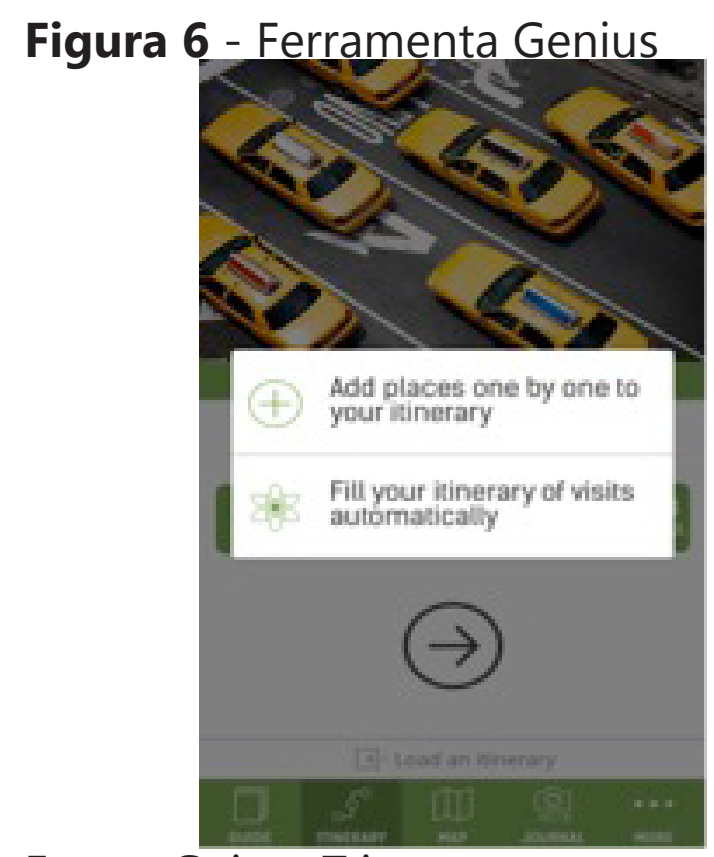

Fonte: Guia mTrip.

O mTrip ainda apresenta a opção de adicionar um local no caso do usuário visitar algum lugar de New York que não conste no guia, mediante o preenchimento de informações requisitadas pelo aplicativo. Assim, o usuário escolhe a categoria temática do local a ser adicionado, além de especificar o tipo de atrativo para incluir as informações exigidas pelo guia, de modo que o local seja registrado com sucesso.

Ademais, ao abrir a ficha técnica de determinado atrativo, o usuário pode avaliá-lo publicando impressões sobre a visita, sendo que todo comentário fica salvo e qualquer pessoa que baixe o aplicativo terá acesso às informações. Fotos e anotações produzidas pelo próprio usuário podem ser divulgadas junto com o itinerário do viajante no site (www.mtrip.me), e o link pode ser compartilhado pelo Facebook ou enviado por e-mail. Caso o usuário queira apenas compartilhar uma foto ou imagem existente no guia, ele pode enviá-la como cartão postal 
via Facebook e e-mail. Há também o sistema de localização do aplicativo que permite contextualizar a foto no mapa, ou seja, indicar exatamente o local onde a foto foi tirada.

Ao contrário do guia Lonely Planet, o mTrip permite tanto o compartilhamento da viagem quanto o armazenamento de informações úteis dos próprios usuários no aplicativo. Dessa forma, o viajante se mantém mais informado e, por ter acesso a diversos tipos de informação, torna-se mais seletivo sobre o que fazer e consumir no destino.

Na categoria interatividade, foi observado se os guias disponibilizavam o serviço de geolocalização via GPS, funcionalidade presente nos dois aplicativos pesquisados. Os sistemas computacionais móveis são sistemas que podem facilmente ser movidos ou são capacitados de forma a serem utilizados enquanto estão em movimento, oferecendo recursos e características específicas não encontradas em outros sistemas comuns (TORRES, 2011). Assim, vale analisar se os aplicativos usufruem desses recursos já existentes nos smartphones.

O guia Lonely Planet oferece o serviço locate me (localize-me) integrado a um mapa interativo da cidade de New York. A partir da localização do usuário, o mapa mostra locais próximos, como restaurantes, acomodações, atrativos, etc. Todas essas categorias são representadas por ícones no mapa. Consequentemente, ao clicar em um ícone, o usuário é direcionado para a ficha técnica do atrativo. O contrário também acontece, pois ao acessar o conteúdo sobre certo local, existe a possibilidade de situá-lo no mapa. O usuário pode ter a rota traçada do seu local atual para o destino desejado. Esse tipo de serviço representa como esses novos sistemas móveis se aproveitam da personalização e da localização de uma maneira nova (NORM..., 2011), além de oferecer um acesso irrestrito a diversas informações úteis com um bom nível de interatividade (ANDRADE; MAIA; MAIA, 2011).

Entretanto, para que o serviço seja utilizado, é necessário que o usuário tenha conexão à internet e que esteja de fato na cidade de New York (Figura 7). 
Figura 7 - Mapa interativo on-line

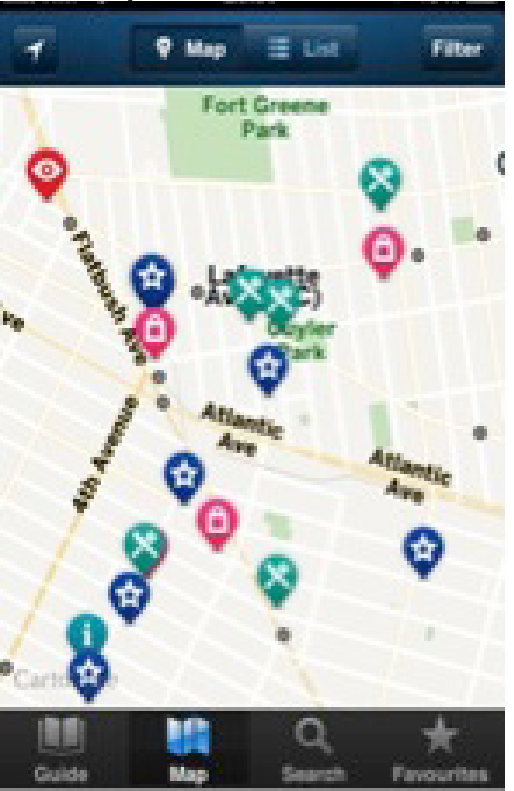

Fonte: Guia Lonely Planet.
Figura 8 - Realidade aumentada

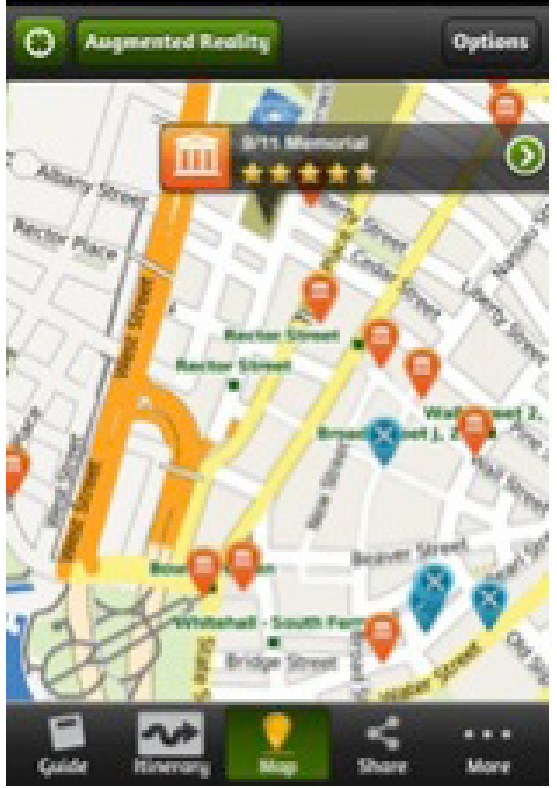

Fonte: Guia mTrip.

Algo similar ocorre com o aplicativo mTrip, todavia, caso o viajante não tenha acesso à internet, ele pode informar seu endereço atual e a rota é traçada por meio do serviço de mapa de navegação off-line. Nos mapas dos dois aplicativos, o usuário pode escolher a visualização por tipo de atrativo turístico. Dessa maneira, os serviços de localização existentes nos guias possibilitam que o viajante tenha acesso a informações em tempo real de acordo com o contexto, isto é, considerando as necessidades e a localização atual (LAMSFUS et al., 2013).

Partindo do pressuposto de que guias e mapas são fundamentais em viagens, usados frequentemente em combinação enquanto os viajantes visitam e descobrem o que fazer, os mapas são ainda mais essenciais por auxiliar um turista a ter uma ideia da localização geográfica em um determinado destino (DIAZ LUQUE; CORREA, 2012). Ambos os aplicativos podem aprimorar tais recursos se utilizarem a capacidade de personalização característica dos smartphones. Aliado ao serviço de realidade aumentada, esses aspectos são considerados fatores de inovação para os dispositivos móveis, na concepção de Jesus e Silva (2009).

Vale destacar que o serviço de realidade aumentada é disponibilizado somente no aplicativo mTrip (Figura 8), que é acionado quando o viajante encontra-se nos limites da cidade de New York. Portanto, observa-se que o 
serviço tem capacidade tecnológica para, literalmente, conduzir ou mostrar o caminho ao viajante, fornecendo informações precisas e contextualizadas sobre o destino, ampliando sobremaneira a experiência do viajante, que não se restringe aos dados básicos que o destino tem a ofertar (JESUS; SILVA, 2009).

\section{VERSÕES MULTILÍNGUES}

O uso de fontes de informação para auxiliar na pesquisa, planejamento e realização da viagem é imprescindível para o viajante, consequentemente, a internet e as TICs adquirem relevância como distribuidoras de informação turística, à medida que garante o acesso de maneira rápida e objetiva. Nesse contexto, a tecnologia móvel figura como um facilitador para que o usuário possa acessar variados conteúdos de qualquer ponto.

Por sua vez, a informação sobre destinos turísticos é procurada por viajantes de diferentes nacionalidades, tanto que os guias impressos são vendidos em diversos idiomas para abranger um público internacional e tão diversificado como o composto pelos viajantes. Dessa forma, ao analisar a existência de versões dos aplicativos de guias de viagens sobre New York em múltiplas línguas, constatou-se que no guia Lonely Planet somente o idioma inglês estava disponível. Já no aplicativo da Apple Inc. mTrip, estavam disponíveis versões do guia nos seguintes idiomas: inglês, francês, espanhol, alemão e japonês.

A ausência de versões do conteúdo para outros idiomas acaba por limitar o alcance internacional do produto, especificamente, o alcance do uso desses aplicativos, que não encontram limites físicos de tempo e espaço (FUENTETAJA et al., 2014), nem de nacionalidade para serem utilizados (DIAZ-LUQUE; CORRÊA, 2012).

\section{CONSIDERAÇÕES FINAIS}

A informação torna-se fundamental no que diz respeito ao planejamento de uma viagem. Dessa forma, os avanços tecnológicos são componentes importantes para o seu gerenciamento de forma efetiva e para que seja distribuída velozmente. 
Por meio de uma análise comparativa dos aplicativos Lonely Planet e mTrip, constatou-se que ambos desempenham bem a função de guiar o viajante independente no contexto do turismo móvel. No que diz respeito ao conteúdo informativo presente nos aplicativos, predominam similaridades entre os tópicos gerais, desde formas de acesso ao destino até informações sobre atrativos, empresas turísticas e informações de utilidade pública. A localização de pontos de interesse torna-se relativamente fácil ao usar os mapas interativos disponíveis tanto no aplicativo mTrip quanto no Lonely Planet. Entretanto, somente o mTrip permite a utilização do mapa interativo em modo off-line, ou seja, em situações que o viajante não tenha acesso à rede internet via wi-fi ou tecnologias $3 G$ e 4G.

Um aspecto diferencial entre os dois guias turísticos refere-se ao modo como a informação é abordada. Ao enfatizar a questão da mobilidade como pano de fundo, dando suporte ao conteúdo informativo, o mTrip destaca-se por seu uso estar atrelado à movimentação do viajante no destino, sendo as informações organizadas de forma objetiva e direta. Já o guia Lonely Planet carece de informações mais objetivas, ao exibir parágrafos longos que tornam a leitura cansativa e não leva em conta a produção de conteúdo para o formato de dispositivos móveis, às vezes, com telas pequenas, além da dificuldade de lê-las, de acordo com a luminosidade do local.

Outras diferenças de estrutura são evidenciadas nas categorias de $m$-Commerce, interatividade e versões multilíngues, quando o desenvolvimento das TICs se reflete diretamente nos canais de distribuição do turismo em plataformas móveis. Sobre as práticas de $m$-Commerce, o mTrip mais uma vez observa o potencial da tecnologia móvel, ao possibilitar a reserva de hotel via aplicativo graças a uma parceria com a Booking.com. Vale ressaltar que o novo consumidor está sempre conectado, buscando otimizar seu tempo, assim $m$-Commerce figura como uma necessidade. Como o cenário de tomada de decisões sobre viagens está mais dinâmico, com consumidores baseando essas decisões em ofertas de última hora, saber se aproveitar das possibilidades de utilização dos sistemas móveis é uma vantagem.

Neste sentido, se antes as três fases da viagem pareciam ser bem distintas, com o suporte da tecnologia móvel elas se mesclam, pois agora o viajante pode alterar o roteiro e seguir para outra cidade comprando a passagem e 
reservando o hotel horas antes. Além disso, o viajante pode compartilhar opiniões, fotos e vídeos enquanto se encontra no destino, tornando a fronteira entre pré, durante e pós-viagem quase inexistente.

Com relação à interatividade, o guia turístico Lonely Planet não explora formas de interação com o usuário, algo que se limita ao serviço de localização por meio do mapa interativo para traçar rotas. Já o mTrip procura explorar ao máximo o potencial interativo da tecnologia móvel, proporcionando ao viajante a opção de compartilhar dados sobre a viagem, por meio de um site próprio do guia, pelo Facebook e e-mail, e também usando o serviço de realidade aumentada. Não surpreendentemente, devido aos avanços tecnológicos, o consumidor está constantemente conectado, portanto, mais informado sobre os produtos e os serviços e mais livre no quesito de apropriação da informação.

O idioma foi outro elemento divergente no estudo comparativo. O mTrip oferece versões em inglês, francês, espanhol, alemão e japonês, enquanto o Lonely Planet apenas oferece conteúdo no idioma inglês, o que impede a utilização do aplicativo por pessoas que desconheçam tal linguagem. Ao comprar um guia impresso, o viajante tem a opção de escolher o idioma de origem, dessa maneira, é curioso perceber que a empresa BBC Worldwide não aproveitou as vantagens trazidas pela mobilidade, como a capacidade de ultrapassar barreiras como a colocada pela questão da língua. Trata-se de um aspecto negativo e surpreendente, levando-se em conta que a marca Lonely Planet tem no portfólio guias turísticos em 14 idiomas.

Em síntese, ambos os aplicativos são ricas fontes de consulta para o viajante. Todavia, há aspectos a serem aprimorados no que concerne à tecnologia móvel, sobretudo, no guia turístico Lonely Planet, que parece ter transferido as informações contidas no guia impresso ou website, sem considerar as peculiaridades dos dispositivos móveis. A ausência de níveis de comercialização, de interatividade e de versões em outros idiomas comprova que não houve um entendimento sobre as especificidades da tecnologia móvel associada às necessidades ou às mudanças de comportamento do consumidor.

Por ter origem no meio móvel e ser desenvolvido por uma companhia do ramo da computação, o guia turístico mTrip aproxima-se da realidade delineada pela tecnologia móvel e, dada a associação com uma empresa de 
turismo, também demonstra ter domínio em identificar as necessidades do viajante. Os meios portáteis de comunicação conectados à rede proporcionam o deslocamento do acesso para qualquer lugar, representando um nicho de mercado na área do turismo.

O crescimento da mobilidade demonstra como as tecnologias evoluíram em um curto espaço de tempo e foram se adaptando ao cenário atual. Hoje os novos consumidores dependem cada vez mais dos dispositivos móveis para checar e-mails, fazer pesquisas via internet, contatar amigos por redes sociais, comprar e até acessar contas de bancos on-line. Enfim, são as plataformas móveis que entregam experiências ricas em interatividade, interface e usabilidade por meio de aplicativos.

A análise comparativa dos aplicativos de guias turísticos demonstrou a potencialidade que um meio de comunicação móvel tem ao ser explorado em toda a sua extensão e como esse meio pode mudar a forma de interação entre consumidor, produtos e serviços. Por fim, os resultados do estudo podem colaborar no campo de desenvolvimento de aplicativos para o turismo, iluminando questões e aspectos a serem ponderados pelo mercado, e incentivando o investimento na melhoria de produtos e serviços turísticos, de modo a proporcionar uma gestão mais flexível em viagens.

\section{REFERÊNCIAS}

ALLERSTORFER, P. A Survey of Augmented Reality Technology Applied in Mobile Tourism. In: INTERNATIONAL STUDENT CONFERENCE IN TOURISM RESEARCH, 1., 2013, Salzburg. Proceedings... Salzburg: Books on Demand, 2013, p. 90-100.

ANDRADE, R. M. C.; MAIA, M. E. F.; MAIA, P. H. Desenvolvendo aplicações móveis integradas a redes sociais para o suporte de turistas no Brasil. In: SEMINÁRIO DE SOLUÇÕES TECNOLÓGICAS PARA A COPA DO MUNDO E OS JOGOS OLÍMPICOS NO BRASIL, 1., 2011 , São Paulo. Anais... São Paulo: FIT, 2011.

AOQUI, C. Desenvolvimento do Segmento Backpacker no Brasil sob a Ótica do Marketing de Turismo. 2005. 217f. Monografia (Graduação em Administração)- Faculdade de Economia, Administração e Contabilidade, Universidade de São Paulo, São Paulo, 2005. 
APPOLINÁRIO, F. Metodologia da ciência: filosofia e prática da pesquisa. São Paulo: Cengage Learning, 2011.

BROWN, B.; CHALMERS, M. Tourism and mobile technology. In: EUROPEAN CONFERENCE ON COMPUTER SUPPORTED COOPERATIVE WORK, 8., 2003, Helsinki. Proceedings... Helsinki, Kluwer Academic Press, 2003, p. 1-20.

CAMARGO, H. L. Patrimônio Histórico e Cultural. São Paulo: Aleph, 2002.

CORRÊA, C. Mobile Marketing of the Brazilian Tourist Board: Case study of Brazil Mobile application. e-Review of Tourism Research, v. 5, p. 1-6, 2014.

CORRÊA, C; KITANO, C. Gamification in Tourism: Analysis of Brazil Quest Game. e-Review of Tourism, v. 6, p. 1-5, 2015.

DIAS, R.; AGUIAR, M. R. Fundamentos do Turismo: conceitos, normas e definições. Campinas, SP: Editora Alínea, 2002.

DIAZ-LUQUE, P., CORRÊA, C. H. W. Análise dos Websites de Turismo Oficial das Cidades Sede da Copa do Mundo de Futebol de 2014 no Brasil. Revista Turismo \& Desenvolvimento, v. 1, n. 17/18, p. 201-211, 2012.

FDMLA - Pesquisa de uso. Prosper Mobile Insights, 15/08/2012. Disponível em: <http:// www.fdmla.com/smartphone-ou-tablet-pesquisa-de-uso - Smartphone ou tablet->. Acesso em: 3 set. 2012 .

FREIRE-MEDEIROS, B.; MENEZES, P.; NUNES, F. Diários no sentido irrestrito do termo: memórias virtuais de cidades reais. Revista E-Compós, v. 11, n. 1, p. 1-20, 2008. Disponível em: <http://compos.org.br/seer/index.php/e-compos/article/view/272/257>. Acesso em: 20 jul. 2012.

FUENTETAJA, I. G.; SIMON, I. Z.; ARANZABAL, A. R.; ARIZA, M. P.; LAMSFUS, C.; ALZUASORZABAL, A. An analysis of mobile applications classification related to tourism destination. In: INFORMATION AND COMMUNICATION TECHNOLOGIES IN TOURISM, 21., 2014, Dublin. Proceedings... Dublin: Springer, 2014, p. 31-44.

\section{GIL, A. C. Como elaborar projetos de pesquisa. 3. ed. São Paulo: Atlas, 2008.}

HENLEY CENTRE HEADLIGHTVISION/AMADEUS. Future Traveller Tribes 2020: Relatório para a Indústria de Viagens, 2011. Disponível em: <http://pt.scribd.com/doc/18121381/FutureTraveller-Tribes-2020-Versao-em-portugues\#archive>. Acesso em: 12 abr. 2012. 
HUINEN, C. Mobile tourism and Government. An Inventory of European Projects. Heerlen: EC/DC, 2006.

JESUS, C.; SILVA, L. J. O. L. Potencialidades dos serviços móveis de Realidade Aumentada aplicados ao Turismo. In: Congresso da Federação Lusófona de Ciências da Comunicação, 8., 2009, Lisboa. Anais... Lisboa, 2009, p. 2296-2314.

KENNEDY-EDEN, H.; GRETZEL, U. A taxonomy of mobile applications in tourism. e-Review of Tourism Research, v. 10, n. 2, p. 47-50, 2012.

KOSAKA, V. K. I. Distribuição On-line de Informações e Serviços Turísticos para o Segmento de Viajantes Independentes no Brasil - o caso da WHL. TRAVEL. 2009. $96 \mathrm{f}$. Monografia (Graduação em Turismo)- Instituto de Geociências, Universidade Federal Minas Gerais, Belo Horizonte, 2009.

LAMSFUS, C., XIANG, Z., ALZUA-SORZABAL, A., MARTIN, D. Conceptualizing context in an intelligent travel environment in travel and tourism. In: INFORMATION AND COMMUNICATION TECHNOLOGIES IN TOURISM, 20., 2013, Vienna. Proceedings... Vienna: Springer, 2013, p. 1-11.

LOHMANN, G. A tecnologia e os canais de distribuição em Turismo. In: BRAGA, D. C. (Org.). Agências de Viagens e Turismo: Práticas de mercado. Rio de Janeiro: Elsevier, 2008. p. 30-41.

LONELY PLANET. Site oficial. Disponível em: <http://www.lonelyplanet.com/>. Acesso em: 10 set. 2014.

MARIUZZO, P. Guias histórico-turísticos buscam identidade e atrativos nacionais. Revista Ciência e Cultura, v. 61, n. 4, p. 64-65, 2009. Disponível em: <http://cienciaecultura.bvs. $\mathrm{br} / \mathrm{scielo}$.php? script=sci_arttext\&pid=S0009-67252009000400023\&lng=en\&nrm=iso $>$. Acesso em: 1 dez. 13.

MTRIP. Site oficial. Disponível em: <http://www.mtrip.com/>. Acesso em: 10 set. 2014.

NORM ROSE OF TRAVEL TECH CONSULTING INC. The always-connected traveller: How mobile will transform the future of air travel. 2012. Disponivel em: <http://www.amadeus. com/airlineit/the-always-connected-traveller/docs/amadeus-the-always-connectedtraveller-2011-en.pdf>. Acesso em: 3 out. 2013.

NOVA, M. R. Guias Impressos da Cidade de São Paulo: a exposição do patrimônio cultural. In: SEMINÁRIO DE PESQUISA EM TURISMO DO MERCOSUL, 5., 2008, Caxias do Sul. Anais... Caxias do Sul: UCS, 2008, p. 1-11. 
PELLANDA, E. C. Tecnologias móveis para quê, onde e quem? In: STEFFEN, C.; PONS, M. (Org.). Tecnologia Para Quê? Os Dispositivos Tecnológicos de comunicação e seu impacto no cotidiano. Porto Alegre: Armazém Digital Comunicação Ltda., p. 95-109, 2011.

PELLANDA, E. C. Comunicação móvel: das potencialidades aos usos e aplicações. Revista Em Questão, n. 1, p. 89-98, jan./jun. 2009. Disponível em: <http://www.intercom.org.br/ papers/nacionais/2008/resumos/R3-1727-1.pdf>. Acesso em: 2 ago 2012.

PRESTIPINO, M. From Information Behaviour of independent Travellers to Requirements for information Systems. In: INFORMATION AND COMMUNICATION TECHNOLOGIES IN TOURISM, 13., 2006, Vienna. Proceedings... Vienna: Springer, 2006, p. 1-12.

REJOWSKI, M. Turismo no Percurso de Tempo. São Paulo: Aleph, 2002.

RODRIGUES, A.; BECO, A.; TEIXEIRA, L. Guia Turístico em Dispositivo Móvel Baseado em RA- MOBIGUIDETOUR. In: SIMPÓSIO DE EXCELÊNCIA EM GESTÃO E TECNOLOGIA, 8., 2011, Resende. Anais... Resende: UFES, 2011, p. 1-15. Disponível em: <http://www.researchgate. net/publication/228455762_Guia_Turstico_em_Dispositivo_Mvel_Baseado_em_RaMobiguidetour>. Acesso em: 3 ago. 2012.

RODRIGUES, M. C. Para onde foi o "jornalismo turístico"? Análise de capas de revista Viagem \& Turismo em 2007. In: ENCONTRO NACIONAL DA REDE ALCAR, 6., 2008, Porto Alegre. Anais... Porto Alegre: UFRGS, 2008, p. 1-15.

ROUGH GUIDES. 2013. Disponível em: <http://www.roughguides.com>. Acesso em: 3 out. 2012.

SALGUEIRO, V. Grand Tour: uma contribuição à história do viajar por prazer e por amor à cultura. Revista Brasileira de História, n. 44, p. 289-310, 2002.

SCHNEIDER, S.; SCHIMITT, C. J. O uso do método comparativo nas Ciências Sociais. Cadernos de Sociologia, v. 9, p. 49-87, 1998.

SCHWINGER, W.; GRÜN, CH.; PRÖLL, B.; RETSCHITZEGGER, W.; SCHAUERHUBER A. Contextawareness in Mobile Tourism Guides - A Comprehensive Survey. Technical Report. Johannes Kepler University Linz: IFS/TK, 2005.

SMITH, W. W.; LI, X.; PAN, B.; WITTE, M.; DOHERTY, S. T. Tracking destination image across the trip experience with smartphone technology. Tourism Management, v. 48, p. 113-122, 2015.

TORRES, C. E. Mobilidade: Computação móvel, dispositivos e aplicativos. Disponível em: $<$ http://www.slideshare.net/cetorres/palestra-mobilidade-computao-mvel-dispositivos-eaplicativos > . Acesso em: 1 out. 2012. 
UNY, J. The Tourist Gaze. London: Sage Publications, 1991.

XU, F.; WEBER, J.; BUHALIS, D. Gamification in Tourism. In: INFORMATION AND COMMUNICATION TECHNOLOGIES IN TOURISM, 21., 2014, Dublin. Proceedings... Dublin: Springer, 2014, p. 525-537.

XU, F.; TIAN, F.; BUHALIS, D.; WEBER, J. Marketing Tourism via Electronic Games: Understanding the Motivation of Tourist Players. In: INTERNATIONAL CONFERENCE ON GAMES AND VIRTUAL WORLDS FOR SERIOUS APPLICATIONS, 5., 2013, Poole. Proceedings... Poole, United Kingdom, 2013, p. 1-8.

WANG D.; XIANG, Z.; FESENMAIER, D. R. Adapting to the mobile world: A model of smartphone use. Annals of Tourism Research, v. 48, p. 11-26, 2014.

WTTC - WORLD TRAVEL AND TOURISM COUNCIL. Travel and Tourism 2011. Disponível em: <http://www.wttc.org/research/annual-review/z. Acesso em: 13 jul. 2012. 